\title{
Fernando Población del Castillo y la arquitectura española durante el Franquismo
}

\author{
Sara Núñez Izquierdo \\ Universidad de Salamanca \\ saranunez@usal.es
}

RESUMEN: En 1947 el arquitecto Fernando Población finalizó sus estudios en la Escuela Técnica Superior de Arquitectura de Madrid y, desde entonces hasta finales de la década de 1970, se convirtió en uno de los técnicos más representativos y prolíícos de la ciudad de Salamanca. Ejerció como arquitecto municipal, además de técnico de la Obra Sindical del Hogar, del Instituto Nacional de la Vivienda y de la propia Universidad de Salamanca. Igualmente, pudo compaginar estas responsabilidades con la práctica liberal de su profesión, diseñando inmuebles en los que fue evolucionando hasta lograr el paso definitivo hacia la modernidad, convirtiéndose en uno de los abanderados de esta tendencia en esta localidad.

PALABRAS CLAVE: Población del Castillo; Siglo XX; Arquitectura historicista; Arquitectura contemporánea; Salamanca; Arquitectura española.

\section{Fernando Población del Castillo and the Spanish Architecture during Franco's Dictatorship}

ABSTRACT: In 1947 the architect Fernando Población completed his studies at the Superior Technical School of Architecture of Madrid and from then until the late 1970s, became one of the most representative and prolific architects in the city of Salamanca. He worked as municipal architect, as well as for the Obra Sindical del Hogar, the National Housing Institute and the University of Salamanca. In addition, he combined these responsibilities with his profession, designing buildings in which his work evolved to achieve the definitive step toward modernity, becoming one of the leaders of this trend in this city.

KEYWORDS: Población del Castillo; Building Types; XX Century; Historical Architecture; Contemporary Architecture; Salamanca; Spanish Architecture.

Recibido: 11 de abril de 2017 / Aceptado: 01 de julio de 2017.

\section{Fernando Población del Castillo}

Fernando Población nació en Salamanca en el mes de diciembre de 1917, hijo de Casimiro Población Sánchez (1886-1940), catedrático de Ginecología de las Universidades de Salamanca y de Madrid, y de Carmen del Castillo Montero (fallecida en 1960). La familia Población del Castillo estaba compuesta por cinco hermanos, de los cuales Fernando fue el único que tuvo clara su inclinación por la arquitectura, motivo por el que preparó el examen de acceso a esta carrera en la Escuela Técnica Superior de Arquitectura de Madrid, en la que ingresó en 1934, titulándose en junio de $1947^{1}$. El estallido y posterior desarrollo de la Guerra Civil interrumpieron sus estudios, que retomó en el curso académico 1940-1941, tras concluir el conflicto. Su interés por la arquitectura fue compartido por su primo Eleuterio Población Knappe (1928-2011), titulado en 1954 y artífice de singulares y modernos edificios levantados entre las décadas de los cincuenta y los setenta en la capital de España, caso de los hoteles Eurobuilding I en la calle Padre Damián (1965) y Eurobuilding II en la calle Orense, (1979) además del conocido Edificio Beatriz de 1964 en la calle Velázquez (Delgado, 2013).

Cómo citar este artículo: NÚÑEZ IZQUIERDO, Sara, «Fernando Población del Castillo y la arquitectura española durante el Franquismo", Boletín de Arte-UMA, n. ${ }^{\circ} 38$, Departamento de Historia del Arte, Universidad de Málaga, 2017, pp. 127-140, ISSN: 0211-8483, DOI: http://dx.doi.org/10.24310/BoLArte.2017.v0i38.3261 
Una vez titulado, Fernando Población instaló su estudio en Salamanca, en la céntrica calle Azafranal y, diez años después, en 1957, cambió de dirección y se trasladó a un inmueble diseñado por él mismo en la Gran Vía, dotado de un amplio ático, donde se custodia en la actualidad su archivo particular. Uno de los motivos que justificó su regreso a la ciudad natal, donde se encuentra el grueso de su producción, fue su matrimonio con la salmantina María Teresa Íscar Sánchez. Casados en 1945, vivieron juntos en Madrid los dos últimos años de estudios del arquitecto y, una vez finalizada la etapa formativa, no dudaron en volver a la capital salmantina, donde residían las familias de ambos. Fruto de esta unión nacieron cuatro hijos, de los cuales únicamente Fernando (nacido en 1951) ha seguido los pasos de su padre al estudiar la carrera en la Escuela Técnica Superior de Madrid, donde se tituló en 1983.

Cinco meses después de fijar su residencia en Salamanca, Fernando Población fue nombrado arquitecto municipal de la localidad. Este sería el primero de los cargos oficiales que desempeñaría a lo largo de su trayectoria profesional, ya que dos años después, en 1949, fue designado arquitecto asesor de la Obra Sindical del Hogar. Compaginó ambas obligaciones hasta mayo de 1950, fecha en la que dimitió de su puesto en el Consistorio para ocupar el de Jefe de la Delegación Provincial de la Vivienda en la misma ciudad a cargo del Instituto Nacional de la Vivienda, labor que desempeñó hasta enero de 1969, año en el que solicitó una excedencia que el Ministerio le concedió, siendo sustituido por Francisco Javier Rey Harguindey, nacido en 1941 y titulado en 1965 (S.A., 1960: 1; S.A., 1969a: 5).

A partir de finales de la década de los sesenta, desarrolló una prolífica etapa en su carrera dedicada a los encargos particulares y concurriendo a concursos públicos. Entre los últimos cabe señalar varios edificios salmantinos como el del Hospital Clínico, de 1968, situado en el paseo de San Vicente, aunque el proyecto seleccionado fue rubricado por Martín José Marcide Odriozola (1916-1972) que se tituló en 1943 (S.A., 1969b: 10; S.A., 1969c: 1, 3; S.A., 1969d: 1, 5-6) y el Instituto Provincial de Sanidad en la avenida de Portugal, de 1968, certamen en el que resultó seleccionada su propuesta, así como el del parador de Turismo, de 1973, que nunca pasó de los planos (S.A., 1973: 3; Francia, 1976: 3; Casado, 1977: 3).

De carácter introvertido y reservado, el arquitecto salmantino dedicó buena parte de sus momentos de asueto a su familia, así como a viajar, siendo Egipto uno de los destinos favoritos al ser un apasionado de su cultura. Fernando Población del Castillo falleció en febrero de 2002, a la edad de ochenta y cinco años, en la ciudad de Salamanca, sin que fuese publicado ningún sentido obituario por expreso deseo de la familia.

\section{Fernando Población, arquitecto municipal}

Como avanzamos, Fernando Población ejerció durante tres años como arquitecto urbanista en el Consistorio de Salamanca, ciudad que a partir de la década de los cuarenta procedió a la regeneración arquitectónica de su centro histórico y urbanizó su ensanche. En alusión a este último, Población examinó y supervisó numerosos informes relacionados con las viviendas obreras que por aquel entonces se estaban levantando fuera del antiguo recinto amurallado de la ciudad, con el objetivo de «facilitar vivienda higiénica y alegre a las clases humildes»².

Además de esto, del Castillo intervino como arquitecto municipal en la configuración de uno de los proyectos más ambiciosos acometidos en estos años, el trazado de la Gran Vía, aunque su diseño databa de principios del siglo XX. Uno de sus fines era convertirla en el espacio que acogiese las sedes de organismos vinculados al nuevo Estado y viviendas destinadas a una elitista clase social. Dadas las dificultades que implicaba esta ambiciosa intervención, el Ayuntamiento creó en 1945 la Comisión Especial para la Gran Vía, integrada por concejales y los arquitectos municipales Ricardo Pérez Fernández (1894-1975, titulado en 1922) y Población del Castillo. La idea inicial del diseño de la Gran Vía fue la de levantar una serie de inmuebles cuyos frentes estuviesen inspirados en los pabellones de la Plaza Mayor de la ciudad. Sin embargo, se consideró poco acertada la reiteración de ese modelo, ya que, irremediablemente, produciría una acusada monotonía ${ }^{3}$. Ante estas circunstancias, la citada Comisión concluyó en la conveniencia de aprobar una relativa libertad en la configuración de las fachadas de los edificios, lo que, sin duda, estaba en relación con cierta tentativa de apertura a nuevas formas en materia de arquitectura, en detrimento del historicismo. De todos modos, se da la circunstancia de que Población del Castillo proyectó varios edificios en esta vía, entre los que 


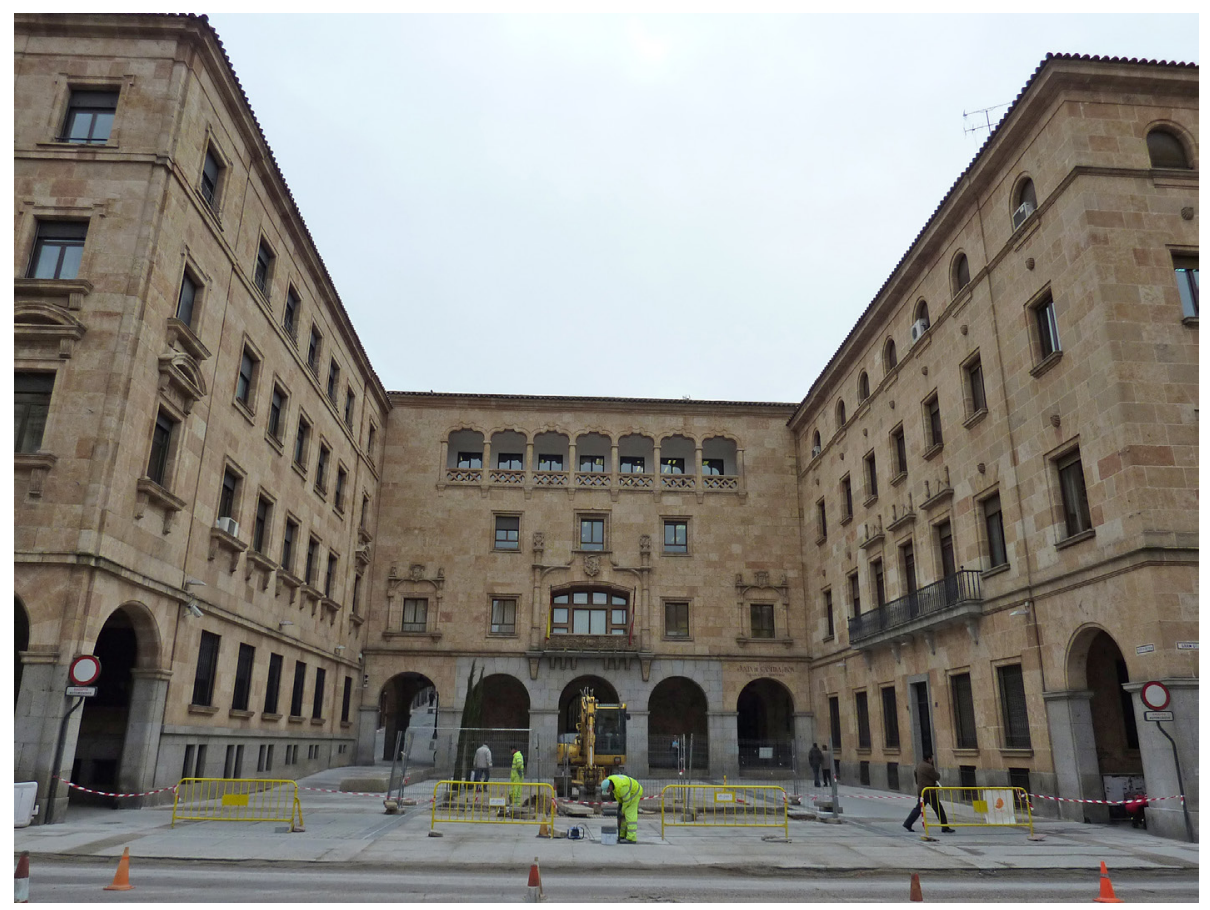

1. Fernando Población del Castillo, Antiguo edificio de la Casa de la Falange, 1955 (actual Gerencia Territorial del Catastro), Calle Gran Vía, Salamanca

destacamos dos de carácter oficial: la sede de la Casa Sindical, 1949, actualmente de UGT, y la Casa de la Falange, de 1955, que a día de hoy alberga las dependencias de la Gerencia Territorial del Catastro ${ }^{4}$ (Gombau, 1955: 4; S.A., 1955a: 4; S.A., 1955b: 1, 6). En ambos casos, el técnico apostó por diseños de inspiración historicista, en los que, no obstante, a diferencia de los levantados por otros profesionales, imperaba la sobriedad decorativa. Llama la atención de la antigua Casa de la Falange no sólo el diseño del frente, sino también su emplazamiento, ya que es el único inmueble de esta avenida que está retranqueado y consta de una plaza previa a la fachada principal, espacio que fue pensado para la celebración de actos públicos. De cara al alzado, Población se inspiró en soluciones propias de la arquitectura local y para ello combinó detalles de estilo neogótico y neorrenacentistas, caso de la tribuna emplazada en el eje central, que destaca por el antepecho con motivos decorativos labrados, mientras que en el último cuerpo sobresale la galería de arcos mixtilíneos, habituales en varios edificios de finales del siglo XVI y principios del XVI de la ciudad [1].

\section{Fernando Población, arquitecto de la Obra Sindical del Hogar}

El desempeño de su cargo como arquitecto municipal supuso, como avanzamos, la familiarización de nuestro personaje con cuestiones constructivas de las viviendas obreras. Esto favoreció que Población acabara formando parte de la plantilla de la Obra Sindical del Hogar y del Instituto Nacional de la Vivienda, organismos fundados durante la dictadura franquista para dar respuesta urgente a la preocupante carencia de infraestructuras y, sobre todo, de viviendas destinadas a la clase obrera.

De este modo, Población fue nombrado en 1949 jefe provincial de la Obra Sindical del Hogar, cargo que desempeñó durante veinte años en los que rubricó los planos y supervisó los trabajos de construcción de un millar de viviendas promovidas por este organismo en Salamanca y su provincia. Este es el caso del grupo Nuestra Señora del Castañar en Béjar (Salamanca), de 1949 (S.A., 1949a: 1; S.A., 1958a: 1, 6). Asimismo, estuvo al frente de las obras 


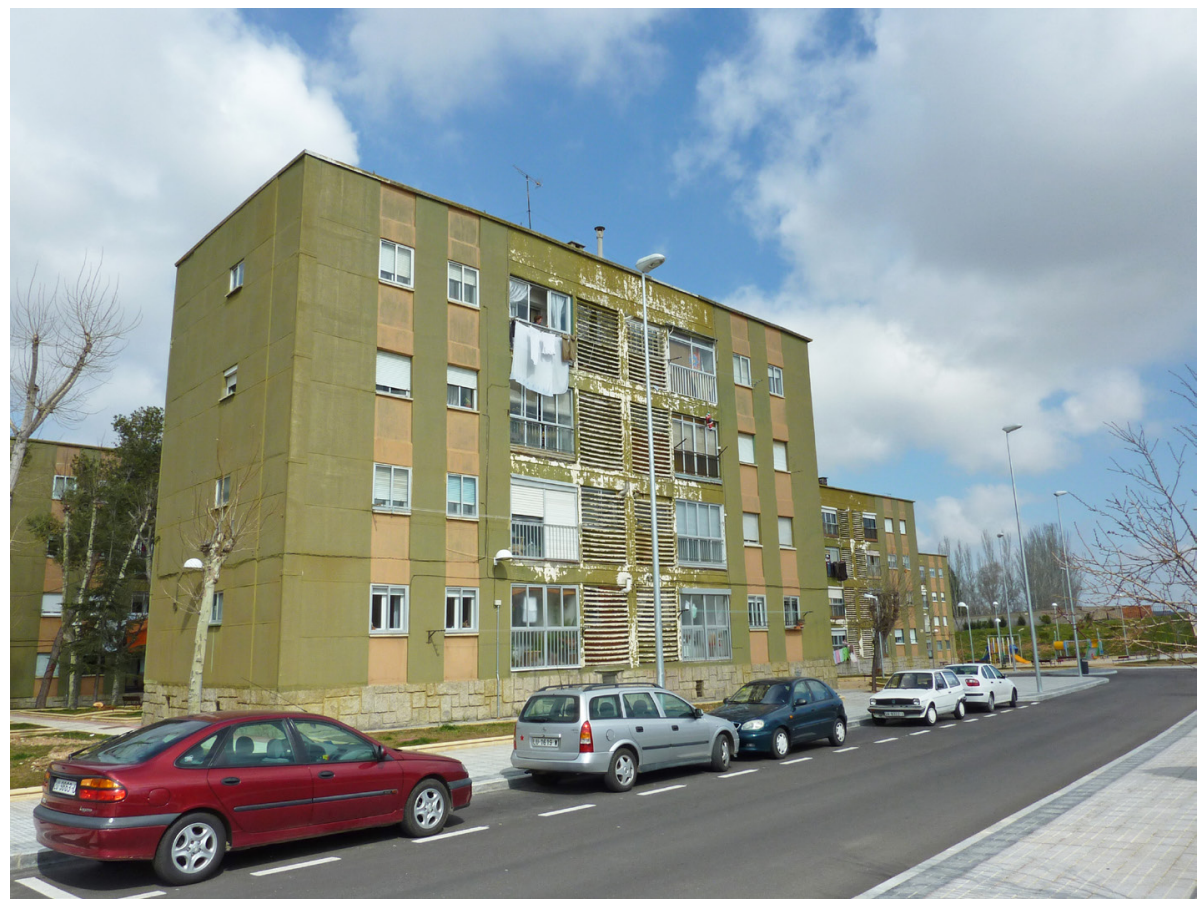

2. Fernando Población del Castillo, Inmuebles del Barrio de San José, 1965

del único poblado dirigido levantado en esta la capital charra durante la dictadura franquista, que corresponde con las 108 viviendas unifamiliares que conforman la primera fase del barrio de Nuestra Señora del Carmen (1949), en el que Población supervisó las obras de autoconstrucción de las citadas viviendas (S.A., 1949b: 6; Gombau, 1950: 6; S.A., 1959a: 11).

Sin duda, el proyecto más ambicioso realizado por del Castillo a cargo de la Obra Sindical del Hogar fue el actual barrio de San José5 [2]. En 1965 el arquitecto recibió el encargo de proyectar 536 viviendas y una guardería emplazadas en un solar situado en la otra orilla del río Tormes, zona en la que apenas se había construido en aquella época, pero que, a partir de entonces, se convirtió en «un barrio nuevo representativo del nivel de vida en la España de hoy» ${ }^{6}$. El conjunto incluía cuatro tipos de viviendas, que oscilaban entre 52 y 103 metros cuadrados, dotadas con un cuarto de estar-comedor, concebido también como distribuidor del resto de las dependencias, en concreto una cocina, un cuarto de aseo, variando el número de dormitorios, siendo el mínimo dos y el máximo cinco.
La configuración de los alzados de todas estas promociones de vivienda obrera era semejante, apostando por inmuebles de extrema sencillez en sus frentes, en los que habitualmente empleó ladrillo cara vista o cubierto con revoco. Se trataba de una arquitectura sobria y desornamentada presidida por criterios higienistas y de economía.

Además de estos inmuebles, Fernando Población también actuó como miembro del jurado, en representación del departamento técnico de la Obra Sindical del Hogar, que calificó uno de los proyectos más significativos de la historia de la arquitectura española de la segunda mitad del siglo XX: el edificio de Sindicatos en Madrid, actual Ministerio de Sanidad, Política Social e Igualdad, situado en el madrileño paseo del Prado (S.A., 1950: 11-12). Según el fallo del concurso de anteproyectos publicado en diciembre de 1949, de las dieciocho propuestas presentadas, se calificaron con la máxima puntuación los diseños de los arquitectos Francisco de Asís Cabrero Torres-Quevedo (1912-2005, titulado en 1942) y Rafael Aburto Renobales (1913-2014, titulado en 1943). La elección constituyó toda una declaración de intenciones por parte del Estado Nue- 


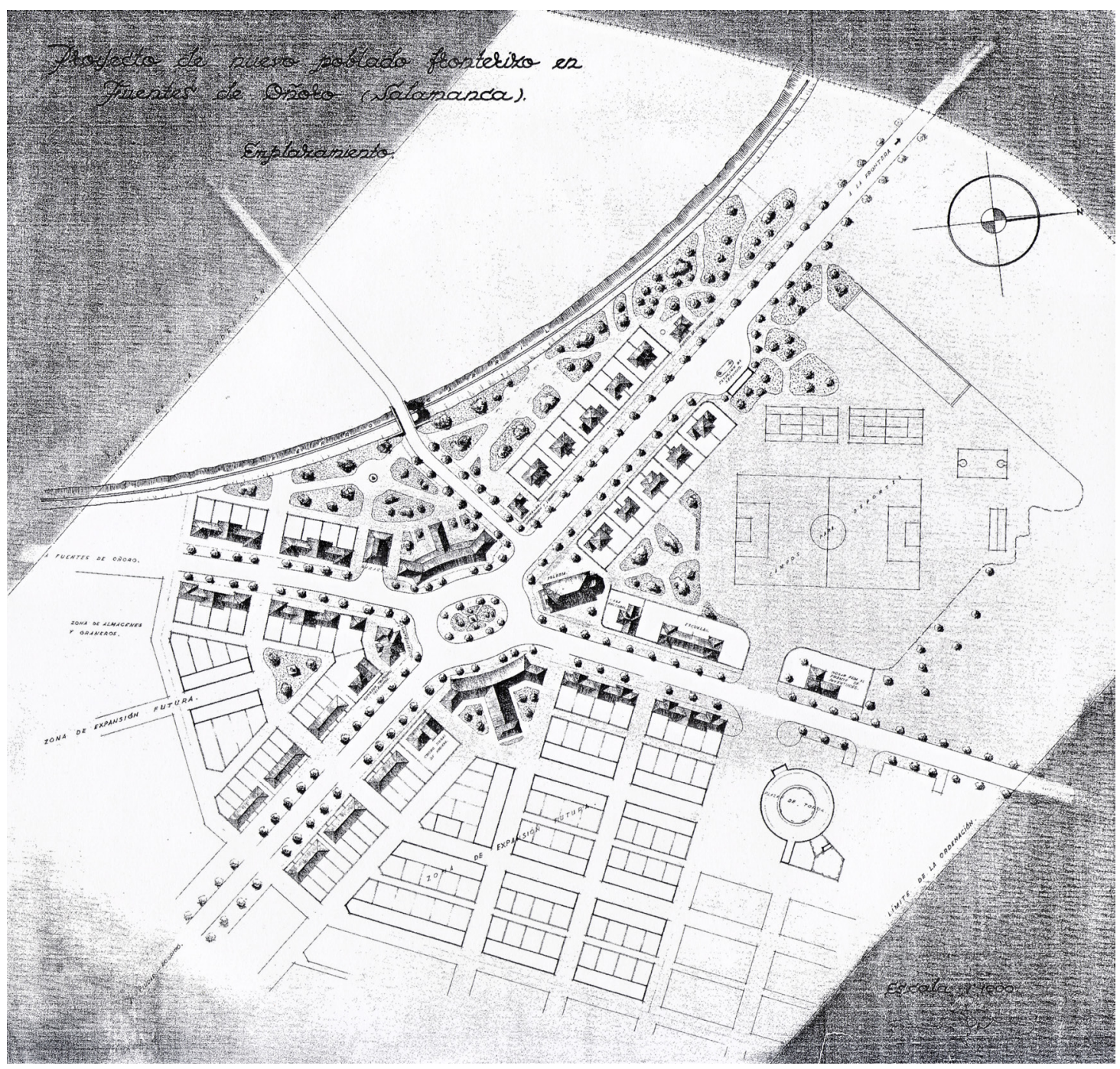

3. Fernando Población del Castillo, Plano del poblado nuevo de Fuentes de Oñoro (Salamanca), 1953

vo, ya que, de manera unánime, se apostó decididamente por la modernidad en la arquitectura oficial, ámbito en el que hasta entonces se había impuesto un historicismo entendido como la corriente adecuada para proyectar la imagen de la dictadura. De este modo, como señaló Ángel Urrutia Núñez, «es innegable que este inmueble presagia nuevos tiempos» (1977: 21). Sin duda, es un inmueble que preludió los inicios de un cambio en la arquitectura española que a principios de la década de los cincuenta se abriría hacia soluciones innovadoras.
Fernando Población, técnico del Instituto Nacional de la Vivienda

Como se ha mencionado, Fernando Población también formó parte de la plantilla de arquitectos del Instituto Nacional de la Vivienda ${ }^{7}$. Durante los diecinueve años que permaneció en este organismo firmó los planos de más de 300 viviendas erigidas en los barrios obreros que experimentaron un rápido crecimiento a partir de la década de los cincuenta, como fue el caso de la segunda fase de construcción del barrio de 
San Bernardo (1954), levantado sobre un terreno limitado por la avenida de Filiberto Villalobos y las calles La Gacela y Las Águilas (S.A., 1954c: s.p.; S.A., 1959a: 11), o la promoción de las doscientas viviendas obreras del barrio Garrido (1963), situadas en las calles Los Cedros, El Trébol, Los Cipreses y Cañas $^{8}$. En estos inmuebles desarrolló propuestas similares a las señaladas en el caso de las obras promovidas por la Obra Sindical del Hogar.

Población también planificó pueblos de nueva creación para este organismo. El caso más reseñable es el de Fuentes de Oñoro (Salamanca), levantado en 1953 en las márgenes de la carretera E-80 (S.A., 1953: 1; S.A., 1954a, 3; Risueño, 1957: 6) [3]. Se trataba de una localidad fronteriza con Portugal de gran actividad económica, comercial y turística (S.A., 1957: 9; S.A., 1958b: 8; S.A., 1959b: 7). Allí se erigieron sesenta viviendas unifamiliares para los funcionarios adscritos al servicio de aduanas y policía, en las que volvió a apostar por un diseño sobrio, con alzados de ladrillo cara vista sin más decoración que la molduración del propio recerco del hueco, además de una Casa Consistorial y una plaza presidida por una iglesia. Esta última destaca por la modernidad del diseño de la fachada principal, en la que sobresalen los grandes ventanales de formato vertical ajenos a recetas historicistas. En esta dirección conviene aclarar que precisamente hacia ese año Población se reveló como el primer técnico que introdujo soluciones con vocación de diseñar una arquitectura moderna, precisamente gracias a algunos proyectos suyos de tipo religioso [4].

\section{Fernando Población y la práctica liberal de la profesión}

Cambiando de ámbito profesional y como adelantamos, además de estos diseños adscritos a organismos oficiales, Fernando Población ejerció la profesión de forma liberal. No en vano fomentó esta actividad al fundar en 1956 la empresa inmobiliaria Construcciones Gran Vía S.A., gracias a la cual intensificó su actividad en el campo de los proyectos arquitectónicos. Las casas de vecindad constituyen el corpus más numeroso de su producción, pero también forman parte del mismo otras tipologías, como iglesias, conventos, residencias, colegios, sucursales bancarias y facultades universitarias $^{9}$.
A tenor de la producción conservada a día de hoy, se establecen tres etapas en esta parcela de su quehacer en las que se constata la evolución decidida de este técnico. La primera arranca en 1948 y finaliza en 1957, período en el que diseñó principalmente casas de vecindad y arquitectura religiosa, si bien con criterios claramente diferenciados. En estos años desarrolló un estilo en el que se fue despojando del discreto historicismo de sus primeros diseños. Dentro de este apartado, en lo tocante a las viviendas, se aprecia cómo prescindió de todo aquello que acusase inspiración historicista, limitándolo a algunos detalles, como la decoración con pináculos escurialenses, así como otros elementos propios de los motivos ornamentales de los palacios salmantinos del siglo XVI, de las que destaca la variada decoración en los recercos de los huecos así como los medallones. Así se aprecia en el edificio promovido por Fernando Íscar en la calle Álvaro Gil $(1949)^{10}$, el que promovió Carmen del Castillo en la Gran Vía con fachada a la calle Azafranal (1950) ${ }^{11}$, el costeado por la empresa inmobiliaria Berrocal y Cuesta en la calle Bordadores (1954) ${ }^{12}$ [5] o el de Fidel López Mediero en la calle Sol Oriente $(1955)^{13}$.

Si la contención y la sobriedad fueron características en el diseño de estas casas de vecindad, la modernidad definió las obras de carácter religioso que rubricó en esta primera etapa proyectual. Este es el caso de la iglesia erigida en el barrio de la Prosperidad, entonces en pleno crecimiento. En 1952 se aprobó el proyecto del nuevo templo que se levantaría en el paseo de San Antonio, aunque las obras comenzaron dos años más tarde ${ }^{14}$ [6]. Por lo que respecta al interior, el arquitecto diseñó una planta de salón desornamentada, en sintonía con los espacios unitarios que empezó a presidir las ceremonias litúrgicas por aquel entonces, mientras que el alzado principal, sobresale por su novedosa solución en la que dio claras muestras del conocimiento de los diseños de Saenz de Oíza (1918-2000, titulado en 1946) y Luis Laorga Gutiérrez (1919-1990, titulado en 1946), ya que, en cierta manera, se inspiró en la basílica hispanoamericana de Nuestra Señora de la Merced (1950) de Madrid. Sin embargo, Fernando Población fue todavía más rotundo en su distanciamiento del historicismo con el proyecto del colegio de Santo Tomás de Villanueva (1955), promovido por los padres Agustinos Recoletos en la carretera de Zamora (S.A., 1955c: 6; S.A., 1958c: 3). De lo proyectado por el arquitecto se aprecia la búsqueda de una marcada sobrie- 
4. Fernando Población del Castillo, Iglesia del poblado nuevo de Fuentes de Oñoro

(Salamanca), 1953

5. Fernando Población del Castillo, Edificio de la empresa Berrocal y Cuesta,

1954, Calle Bordadores
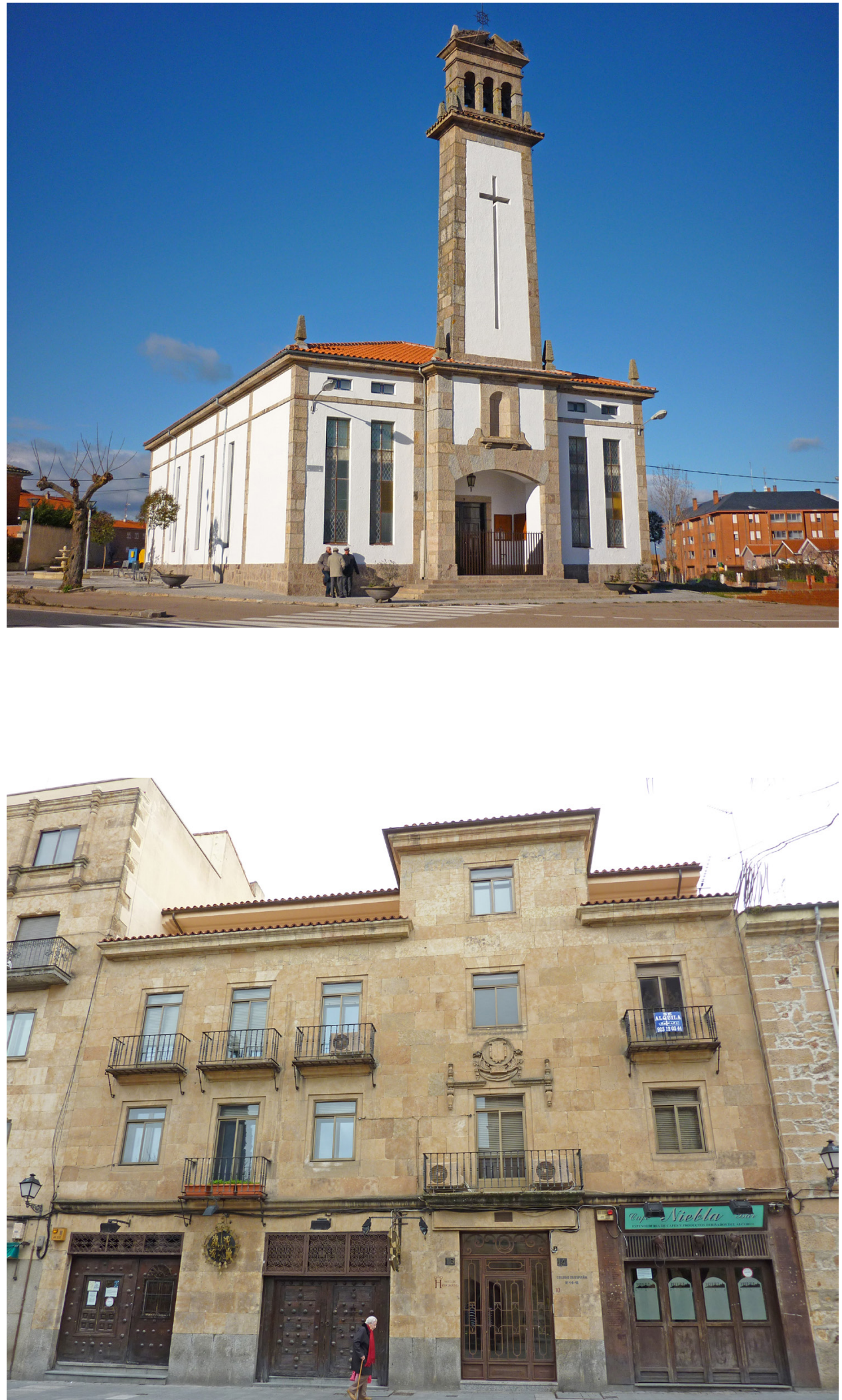


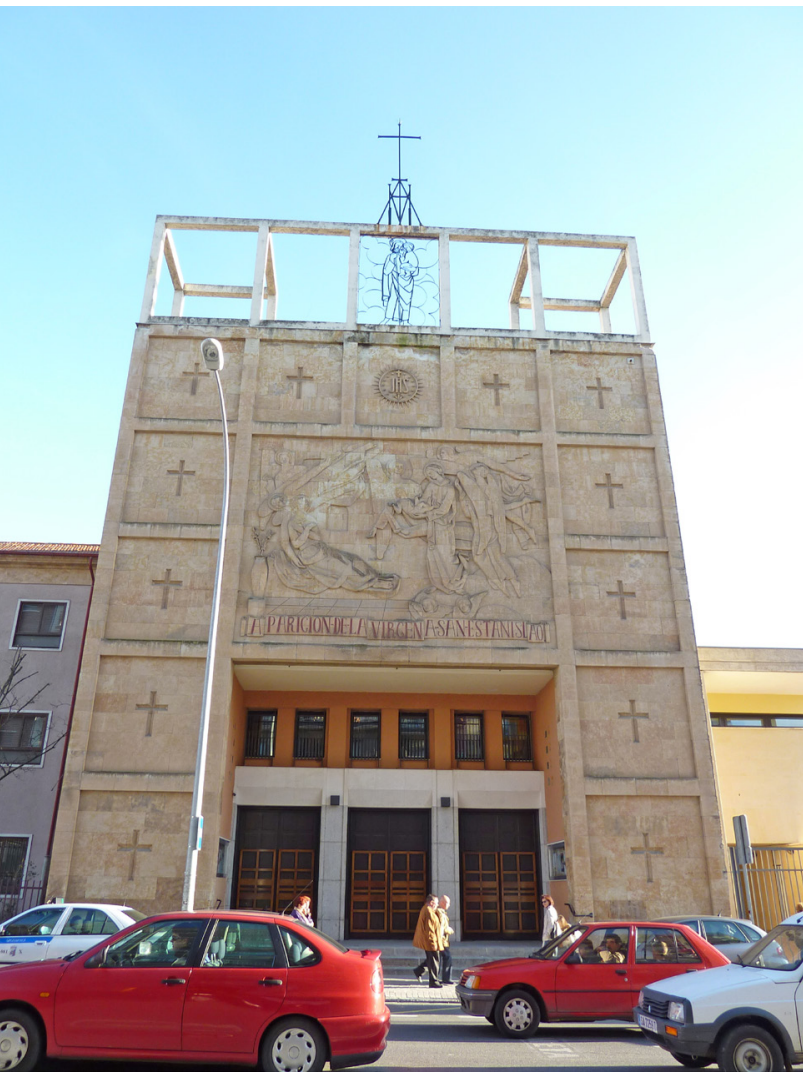

6. Fernando Población del Castillo, Iglesia del Barrio de la Prosperidad, 1952, Paseo de San Antonio

dad, llegando a afirmar que «consideramos trasnochados los equilibrios arquitectónicos antiguos, con pobres réplicas de la monumental arquitectura salmantina, como se observa en algunos edificios de reciente construcción ${ }^{15}$.

La segunda etapa proyectual de Fernando Población arranca en el año 1957 y se dilata hasta 1963, siendo este un período en el que fue latente la influencia del Estilo Internacional en su producción.

Por lo que respecta a sus casas de vecindad, en estos años el arquitecto viró hacia diseños novedosos en comparación con lo proyectado años atrás. Uno de los primeros ejemplos en este sentido fue el edificio de Ramón García Santana situado en la calle Pozo Amarillo (1957) que supuso un paso adelante en su concepción arquitectónica, al configurar un frente con grandes huecos apaisados, amplios balcones corridos, empleo de nuevos materiales como el gresite, aparte de tender al desarrollo en altura ${ }^{16}$ [7]. Junto a éste destacan por los mismos motivos las casas de vecindad de Vicente Sánchez Pablos situada en las calles Sánchez Llevot, García de Quiñones y Rodríguez Fabrés ${ }^{17}$ (1958) [8], cuya singularidad reside en el desarrollo extremo de las solanas, en las que tuvo presente las soluciones de Luis Gutiérrez Soto (1900-1977, titulado en 1923), pero en este caso parecen suspendidas en el aire gracias al empleo, entre otros, de ladrillo de vidrio transparente y la de Andrés Corrionero García en el paseo de Canalejas (1962), en la que apostó por un frente articulado con un balcón corrido que ocupa toda su anchura ${ }^{18}$.

No obstante, este abandono de lo historicista no fue brusco, ya que en ocasiones, quizá determinado por el gusto de los promotores, principalmente religiosos, Población todavía ideó algunas obras dentro de una cierta tradición historicista de la que da buena muestra el colegio Marista Champagnat de 1959, emplazado en la avenida homónima (S.A., 1954b: 6; S.A., 1959c: 3), en el que aún estaban muy presentes los repertorios ornamentales del renacimiento salmantino, y el desaparecido colegio mayor y residencia de las Madres Asuncionistas de 1963, situado en el patio Chico, enfrente de la catedral vieja, para el que concibió un sencillo diseño de fachada, cuyo elemento más llamativo era el alfiz con motivos de bolas que animaba la portada y que recordaba a los de las casas nobiliarias de finales del siglo XV de esta localidad (S.A., 1966: 8).

Por último, incluimos algunas de las obras más innovadoras de su última etapa que comprende desde 1963 hasta finales de 1970. En esta última década Fernando Población redujo su ritmo de trabajo por cuestiones de salud, jubilándose en 1977, aunque esto no fue óbice para diseñar algunos inmuebles en la ciudad a posteriori de ese año, si bien de menor interés que lo hasta aquí expuesto.

Sin duda alguna, uno de los proyectos más notables de este período fue el edificio del Banco de Salamanca (1963) (en la actualidad Banco Popular) y las viviendas colindantes, situadas en la plaza de los Bandos con vuelta a la calle Peña Primera y plaza de Santa Teresa $^{19}$ (S.A., 1963a: 10) [9]. Su emplazamiento en el lado norte de la citada ágora, a escasos metros de la Plaza Mayor, uno de los espacios más singulares de la ciudad, donde se conservan algunas casas nobiliarias de los siglos XV y XVI. La apabullante presencia de ese patrimonio histórico era un desafío para el arquitecto al 


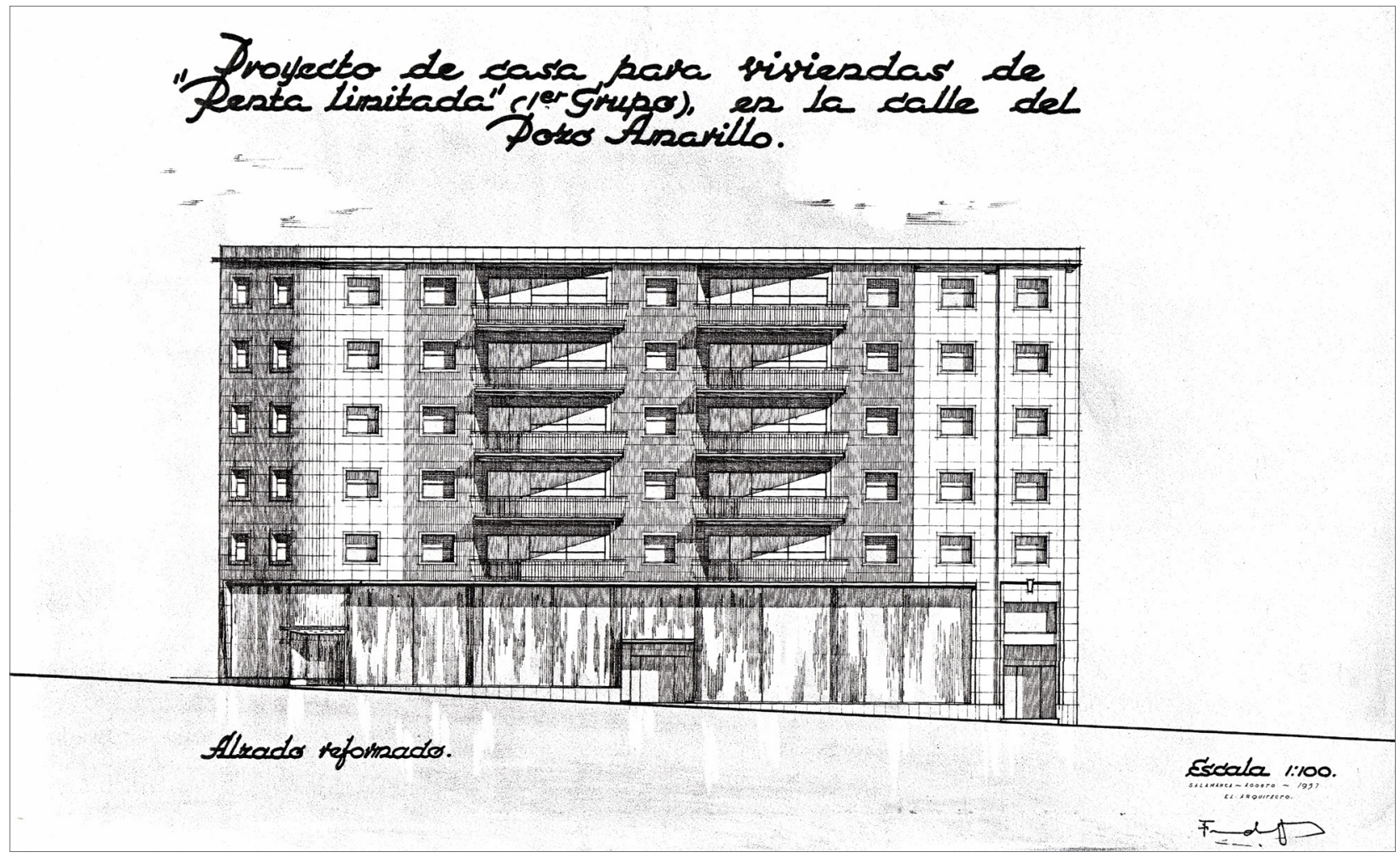

7. Fernando Población del Castillo, Edificio de Ramón García Santana, 1957, Calle Pozo Amarillo

8. Fernando Población del Castillo, Edificio de Vicente Sánchez Pablos, 1958, Calles Sánchez Llevot, García de Quiñones y Rodríguez Fabrés

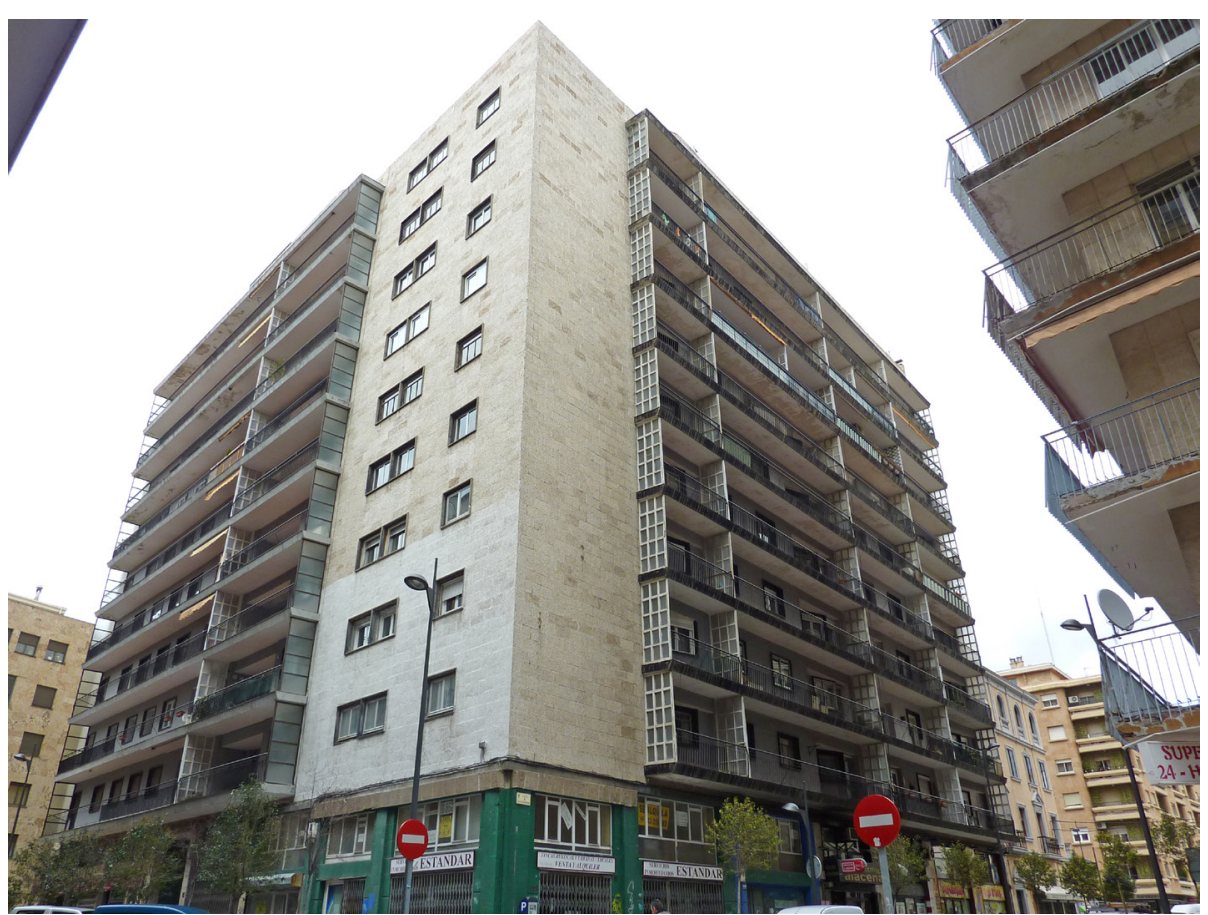




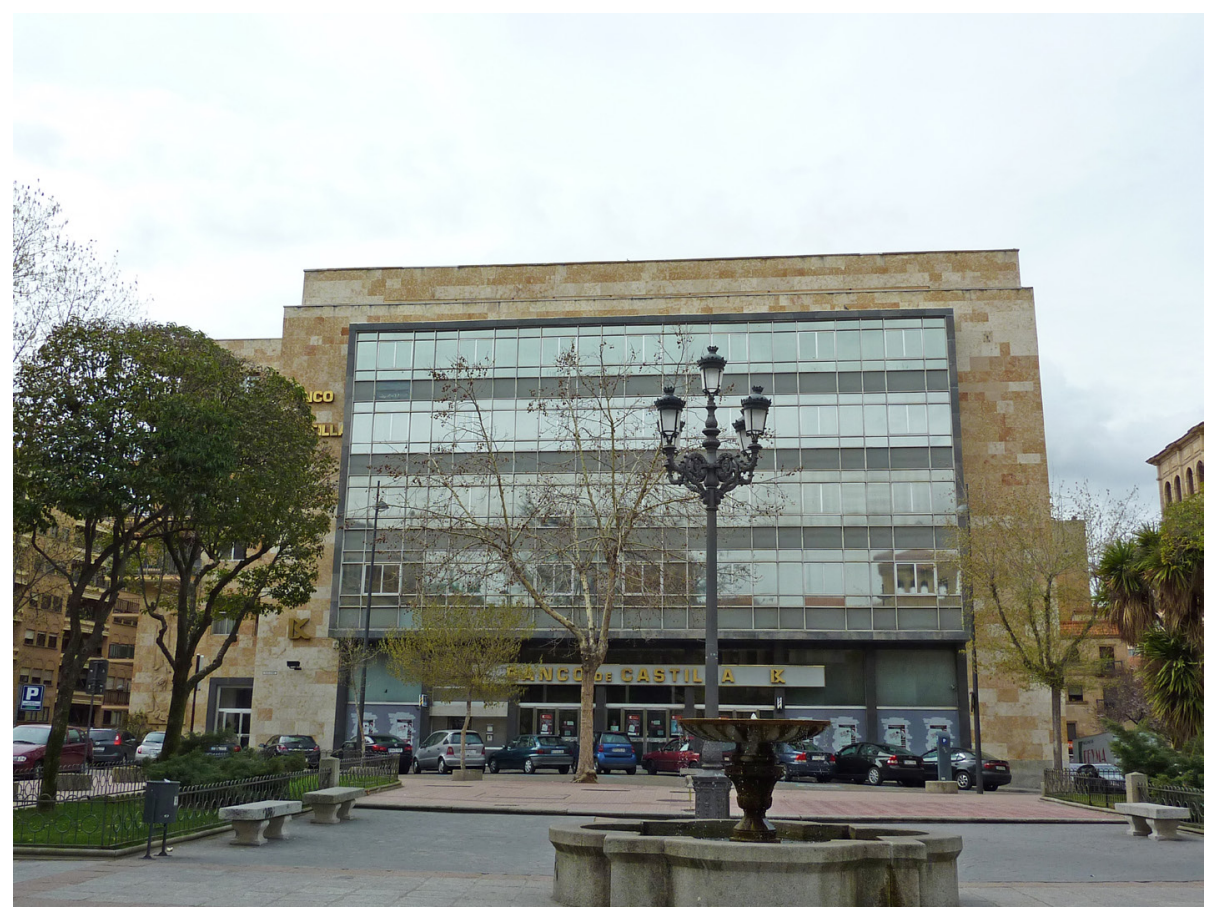

9. Fernando Población del Castillo, Alzado del edificio del antiguo banco de Salamanca, 1963, Plaza de los Bandos

que respondió, sin titubeos, con un diseño que se convirtió en uno de los pioneros de la modernidad arquitectónica de esta ciudad, no sin levantar un cierto revuelo, sobre todo por la configuración de la fachada principal de la entidad bancaria ${ }^{20}$ (S.A., 1963b: 4). Efectivamente, del alzado se confirma que el facultativo buscó la novedad a través de la combinación de materiales habituales en la ciudad, como la piedra arenisca, elemento distintivo de esta localidad, con otros de menor tradición, caso del vidrio y el aluminio con el que articuló el muro-cortina y que, a día de hoy, ha perdido buena parte de su esencia tras una intervención desafortunada. Una vez más, el técnico fue explícito en la memoria del proyectó donde razonó que para el diseño «de las fachadas se han seguido un criterio de composición actual. En ningún caso nos parece justificada la adopción de estilos arquitectónicos antiguos»²1. La diafanidad que preside el exterior se completa en el interior con un concepto espacial unitario con un amplio patio de operaciones en el centro y las mesas de los empleados a su alrededor. De esta manera, Fernando Población se adhirió a la las novedades surgidas en la arquitectura bancaria española a partir de 1957, iniciadas por los arquitectos César Ortiz-Echagüe Rubio (nacido en 1927, titulado en 1952) y Rafael Echaide (1923-1994, titulado en 1955) en la sucursal del Banco Popular Español (1957-1959) en Madrid, entre otras.

Además, Población añadió al alzado de su inmueble un relieve escultórico, ubicado en la parte retranqueada de la fachada principal que corresponde a la zona de viviendas. Se trata de un elemento que introdujo en otros proyectos suyos de estas fechas. Su artífice fue el escultor zamorano José Luis Núñez Solé (1927-1973), quien a través de un diseño de líneas igualmente modernas incorporó una alegoría de la Agricultura. De este modo, con el banco de Salamanca Fernando Población incorporó un claro símbolo de intento de puesta al día en arquitectura, no sólo por lo osado de su propuesta, sino por lo efectista del diseño, que tuvo continuación en la ciudad, ya que, el propio Población volvió a utilizar esta misma receta en la antigua sede del Banco de Vizcaya (1968), hoy Caja España-Duero, situado en la céntrica calle Toro, en la que de nuevo participó con otro relieve de Núñez Solé (S.A., 1968: 8). 


\section{Conclusión}

El caso de Fernando Población es un significativo ejemplo de la dicotomía a la que tuvieron que enfrentarse los arquitectos que, formados académicamente durante la inmediata posguerra, período en el que se impuso el historicismo como la única tendencia posible en el diseño arquitectónico, ejercieron la profesión en los años de la apertura política y económica del país a nivel internacional, lo que supuso la aceptación de la modernidad arquitectónica como imagen de esa puesta al día. Dentro de esta aparente contradicción y enfrentamiento, desempeñaron su carrera arquitectos como el que nos ocupa, quienes, con ingenio y originalidad, incorporaron singulares propuestas $y$, como tales, siguen siendo valoradas a día de hoy. En este sentido, el técnico salmantino dejó constancia de ello a lo largo de su prolíica carrera en la capital charra, donde apostó por la incorporación de diseños que supusieron una ruptura con lo que hasta entonces se había edificado en esta localidad. Tenaz en sus ideas y curioso en el ámbito arquitectónico, Población se erigió en el principal artífice de la modernidad, quien tuvo muy presente lo que se estaba proyectando por aquel entonces en la capital española. Algunos de sus diseños no estuvieron exentos de polémica por lo arriesgado de sus propuestas, justificados, como él mismo sentenció, porque «nuestra misión consiste en crear arquitectura moderna, entiéndase bien, moderna con los materiales tradicionales y con los nuevos, que armonice con el conjunto monumental, sin necesidad de recurrir a viejos estilos, que fueron magníficos en tiempos pasados» (S.A., 1959d: 5).

\section{Notas}

1 Archivo General de Administración Alcalá de Henares, (AGA, Alcalá de Henares) (05) 020 31/2642. Legajo $11457 / 19$.

2 Con estas palabras se resumía el objetivo de la Ley de protección de la vivienda de renta reducida. S.A. (1939), Boletín Oficial del Estado, 20 de abril, p. 2190

3 Así figura en las actas de los plenos celebrados: AMS, Libro n. ${ }^{\circ} 340$. Actas del Pleno del Ayuntamiento. Sesión del 11 de agosto de 1945 , f. 62 ; AMS, Libro n. ${ }^{\circ}$ 344. Actas del Pleno del Ayuntamiento. Sesión del 9 de mayo de 1947, f. 97 v; AMS, Libro n. ${ }^{\circ} 348$. Actas del Pleno del Ayuntamiento. Sesión del 6 de febrero de 1949, f. 52.

4 El proyecto original, sin los cambios posteriores, se conserva en AMS, Caja 6257/4. Expediente 7.

5 AMS, Caja 6627. Expediente 586.

6 AMS, Caja 6698. Expediente 586

7 No hemos hallado documentación que acredite la fecha de la firma del cargo, pero sí numerosas noticias y planos que acreditan su labor como técnico de este organismo durante los años señalados.

8 AMS, Caja 6600. Expediente 165.

9 Las obras proyectadas por Fernando Población del Castillo para la Universidad de Salamanca, entre las que sobresale la Facultad de Ciencias (1964), ha sido ampliamente estudiado por la doctora Sara Cañizal Sardón en su tesis doctoral, motivo por el que no incluiremos en este artículo este apartado. No obstante, señalamos que nunca formó parte de la plantilla del Alma Mater como tal empleado.

10 AMS, Caja 6365/5. Expediente 27.

11 AMS, Caja 6390. Expediente 141.

12 AMS, Caja 6192. Expediente 41.

13 AMS, Caja 6216. Expediente 418.

14 AMS, Caja 6402. Expediente 308

15 AMS, Caja 6210. Expediente 15.

16 AMS, Caja 6454. Expediente 549.

17 AMS, Caja 6489. Expediente 642.

18 AMS, Caja 6593. Expediente 92.

19 AMS, Caja 6599. Expediente 72.

20 Según la prensa, «por sus características este nuevo y moderno edificio va a causar una amplia polémica entre los salmantinos. Los neo tradicionalistas en materia de urbanismo seguirán aferrados a la copia de estilos pretéritos; negarán a los arquitectos de 1963 el derecho a ser fieles a su tiempo y a utilizar los materiales que la técnica pone en sus manos; clamarán al cielo porque en esta plaza no se alce otra falsificación estilística y en su lugar se levante un moderno edificio con un destino funcional específico, cual es el que la citada entidad bancaria va a construir», S.A. (1963b), "Nuevo edificio para la plaza de los Bandos», La Gaceta Regional, 7 de octubre, p. 4.

21 AMS, Caja 6599. Expediente 72. 


\section{Bibliografía}

Archivo General de Administración Alcalá de Henares (AGA, Alcalá de Henares) (05) 020 31/2642. Legajo 11457/19.

Archivo Municipal Salamanca (AMS), Libro n. ${ }^{\circ}$ 340. Actas del Pleno del Ayuntamiento. Sesión del 11 de agosto de 1945 , f. 62.

AMS, Libro n. ${ }^{\circ}$ 344. Actas del Pleno del Ayuntamiento. Sesión del 9 de mayo de 1947, f. 97 v.5

AMS, Libro n. ${ }^{\circ}$ 348. Actas del Pleno del Ayuntamiento. Sesión del 6 de febrero de 1949, f. 52.

AMS, Caja 6257/4. Expediente 7.

AMS, Caja 6627. Expediente 586.

AMS, Caja 6698. Expediente 586.

AMS, Caja 6600. Expediente 165.

AMS, Caja 6365/5. Expediente 27.

AMS, Caja 6390. Expediente 141.

AMS, Caja 6192. Expediente 41.

AMS, Caja 6216. Expediente 418.

AMS, Caja 6402. Expediente 308.

AMS, Caja 6454. Expediente 549.

AMS, Caja 6489. Expediente 642.

AMS, Caja 6402. Expediente 308.

AMS, Caja 6454. Expediente 549.

AMS, Caja 6489. Expediente 642.

AMS, Caja 6593. Expediente 92.

AMS, Caja 6599. Expediente 72.

Boletín Oficial del Estado (1939), 20 de abril, p. 2190.

CASADO, Pedro (1977), «El parador de turismo y el repetidor de TV», La Gaceta Regional, 24 de agosto, p. 3.

DELGADO ORUSCO, Eduardo (2013), La piel dura: Edificio Beatriz, Madrid, Lampreave, Madrid.

FRANCIA SÁNCHEZ, Ignacio (1976), «La obra del parador, parada», La Gaceta Regional, 21 de julio, p. 3.

GOMBAU GUERRA, Gerardo (1950), «Una visita al nuevo barrio de los Pizarrales lleno de realidades y de esperanzas», El Adelanto, 23 de julio, p. 6.

_ (1955), «La futura Casa de la Falange cerrará la Plaza del Caudillo formando frente a la Torre del Aire», El Adelanto, 16 de enero, p. 4.

MARTÍN BUENO, Manuel (1979), «A finales de 1980 se inaugurará el parador nacional», El Adelanto, 27 de diciembre, p. 6.

RISUEÑO GARCÍA, Lorenzo (1957), «El nuevo poblado y los problemas que plantea», La Gaceta Regional, 30 de mayo, p. 6.

S.A. (1949a), «El Delegado Nacional de Sindicatos entregó ayer, en Béjar, las llaves de ciento ocho viviendas protegidas, del grupo de Nuestra Señora del Castañar», El Adelanto, 21 de julio, p. 1.

- (1949b), «La construcción de ciento dieciocho viviendas de prestación personal en los Pizarrales», El Adelanto, 10 de abril, p. 6.

- (1950), «Concurso de anteproyectos para la construcción de la Casa Sindical en Madrid», Revista Nacional de Arquitectura, n. ${ }^{\circ} 97$, pp. 11-12.

- (1953), «Se encomienda al Instituto Nacional de la Vivienda la construcción de un poblado en Fuentes de Oñoro», El Adelanto, 11 de febrero, p. 1.

- (1954a), «El nuevo poblado de Fuentes de Oñoro», El Adelanto, 28 de marzo, p. 3.

- (1954b), «El domingo fue colocada la primera piedra del colegio Marista Champagnat», La Gaceta Regional, 8 de junio, p. 6.

- (1954c), «Nuevas viviendas en Salamanca: los barrios de Vidal, Salas Pombo, Nuestra Señora del Carmen y Virgen de la Vega», El Adelanto, 7 de mayo, $\mathrm{s} / \mathrm{n}$.

- (1955a), "Casa Sindical», La Gaceta Regional, 11 de febrero, p. 4.

- (1955b), «Ayer fue bendecida e inaugurada la nueva Casa Sindical», La Gaceta Regional, 12 de febrero, pp. 1 y 6. 
S.A. (1955c), «Bendición y colocación de la primera piedra del colegio teológico Santo Tomás de Villanueva», El Adelanto, 13 de octubre, p. 6.

- (1957), «Labor del Instituto Nacional de Colonización en nuestra provincia», La Gaceta Regional, 16 de junio, p. 9.

- (1958a), «135 viviendas entregadas ayer en Béjar», La Gaceta Regional, 2 de agosto, pp. 1 y 6.

- (1958b), «El nuevo poblado fronterizo de Fuentes de Oñoro», La Gaceta Regional, 18 de junio, p. 8.

- (1958c), «Será inaugurado el colegio de los Agustinos Recoletos», La Gaceta Regional, 1 de noviembre, p. 3.

- (1959a), «1.484 viviendas construidas en los barrios Salas Pombo y Nuestra Señora del Carmen», El Adelanto, 1 de enero, p. 11.

- (1959b), «Nueva perspectiva aduanera y urbana en la frontera hispano-portuguesa», El Adelanto, 6 de mayo, p. 7.

- (1959c), «Colegio Marista Champagnat», La Gaceta Regional, 7 de agosto, 1959, p. 3.

- (1959d), «Salamanca, problema de arquitectura», La Gaceta Regional, 2 de febrero, p. 5.

- (1960), «Importante reunión urbanística», El Adelanto, 8 de mayo, p. 1.

- (1963a), «Nuevo edificio para la plaza de los Bandos», La Gaceta Regional, 6 de octubre, p. 10.

- (1963b), «Nuevo edificio para la plaza de los Bandos», La Gaceta Regional, 7 de octubre, p. 4.

- (1966), «Admirable reforma de un rincón salmantino», La Gaceta Regional, 26 de julio, p. 8.

- (1968), «El Banco de Vizcaya, en Salamanca, abre hoy al público sus nuevas oficinas en Generalísimo, 42», La Gaceta Regional, 9 de junio, p. 8.

- (1969a), «Sesión de la Comisión Provincial de Urbanismo», La Gaceta Regional, 19 de enero, p. 5.

- (1969b), «Veinticinco millones a la Universidad para ayuda a la adquisición del solar con destino a un nuevo hospital Clínico», El Adelanto, 23 de marzo, p. 10.

- (1969c), «Se aprueba la construcción del hospital Clínico de Salamanca», El Adelanto, 22 de noviembre, pp. 1 y 3.

- (1969d), «El rector de la Universidad informó ayer sobre el proyecto y construcción del hospital Clínico», La Gaceta Regional, 22 de noviembre, pp. 1,5 y 6.

- (1973), «Presentación del proyecto del parador nacional de turismo», La Gaceta Regional, 14 de agosto, p. 3.

URRUTIA NÚÑEZ, Ángel (1977), «Panorama de la arquitectura civil en Madrid: años 50-70», Bellas Artes, n. 57 , p. 21. 
